\title{
Research Progress on the treatment of arsenic pollution by manganese oxide
}

\author{
Huan Yang ${ }^{1}$, Mengxuan Han ${ }^{1}$, Pingping Jiang ${ }^{1 *}$ \\ ${ }^{1}$ Guangxi Key Laboratory of Environmental Pollution Control Theory and Technology, Guilin University of Technology, Guilin, China
}

\begin{abstract}
Arsenic is a kind of protoplasmic poison, which exists widely in the natural environment. Consuming too much arsenic can cause a number of health problems. Manganese oxide plays an important role in arsenic pollution removal technology. In this paper, arsenic hazard and its treatment methods and the application of manganese oxides in arsenic pollution treatment are summarized, and the prospect of research on arsenic pollution treatment by manganese oxides is put forward.
\end{abstract}

\section{Introduction}

Arsenic is widely found in the natural environment, mainly in the form of arsenite (As(III)) and arsenate $(\mathrm{As}(\mathrm{V}))^{[1-3]}$. Arsenic compounds are protoplasmic poisons with metal-like properties that have a wide range of biological effects and are defined as class I carcinogens by the International Agency for Research on Cancer (IARC). Excessive intake of arsenic will cause a series of health problems such as nervous disorders, deformities, melanosis, keratosis and cancer ${ }^{[4]}$. Due to its high toxicity, the concentration of arsenic in drinking water should not exceed $10 \mu \mathrm{g} / \mathrm{L}$ according to China's sanitary standards and the World Health Organization. Arsenic pollution is the world's second largest water health hazard after pathogenic microorganisms ${ }^{[5]}$.

The arsenic pollution problem is particularly prominent in China. The total area of groundwater arsenic content above $10 \mu \mathrm{g} / \mathrm{L}$ is $5.8 \times 105 \mathrm{~km}^{2}$, and the average arsenic content in soil is $11.2 \mathrm{mg} / \mathrm{kg}$, about 1.5 times of the world average $(7.2 \mathrm{mg} / \mathrm{kg})^{[6]}$. According to the 2014 National Soil Pollution Survey Bulletin, the total soil exceeding standard rate in China is $16.1 \%$, and the point exceeding rates of $\mathrm{Cd}, \mathrm{Hg}$, Arsenic, Copper and Lead are $7.0 \%, 1.6 \%, 2.7 \%, 2.1 \%$ and $1.5 \%$ respectively. Arsenic is the primary contaminant among the heavy metal pollutants in soil in China ${ }^{[6]}$. Rice is the main arsenic contaminated food crop in China. The arsenic intake per capita in China is about $42 \mathrm{~g} / \mathrm{d}$, much higher than that in western countries, which is 4 to 4.7 times of the total arsenic intake in the United States, Canada, Australia and France. Among them, the arsenic intake through rice accounts for $60 \%$ of the total arsenic intake ${ }^{[7]}$.

Due to the increasing frequency of arsenic contamination and poisoning, researchers are gradually paying attention to and expanding arsenic pollution removal technology. Manganese oxide plays an important role in arsenic pollution treatment because of its strong oxidation. In this paper, arsenic hazard and its treatment methods and the application of manganese oxides in arsenic pollution treatment are summarized, and the prospect of research on arsenic pollution treatment by manganese oxides is put forward.

\section{Overview of sources and treatment technologies of arsenic pollution}

\subsection{Sources of arsenic pollution}

Arsenic pollution is a global problem. The sources of soil arsenic pollution are complex and can be generally divided into two types: natural sources and man-made sources. Natural sources are mainly parent rocks. In addition, crustal changes, volcanic eruptions, rock weathering, and soil erosion can also produce arsenic. Anthropogenic sources are the pollution caused by human production activities, which can be divided into agricultural pollution and industrial pollution. China is a large agricultural country. Arsenic-containing substances, such as pesticides and herbicides, are essential elements in agricultural production activities. Sewage irrigation and sludge reuse are the main sources of agricultural pollution. Arsenic pollution in the environment is mainly caused by industrial wastes. Specifically, there are mainly two aspects: one is the pollution caused by arsenic-containing soot, waste water, waste gas, waste residue discharged in the mining of arsenic-containing metal ore ${ }^{[8]}$, sintering and smelting process; The second is to use arseniccontaining pesticides to prevent and control the pollution of water, air, soil, fruits and vegetables caused by pests and diseases. It is worth mentioning that metal ores and waste rocks are exposed to the surface in mining for a long time. After long-term rainwater washing and leaching, a large amount of acid wastewater is generated to infiltrate into the soil and cause soil arsenic pollution. At the same time, it will also pollute the water system and farmland, thus endangering human health.

*Corresponding author's e-mail: Jiangpp@glut.edu.cn 


\subsection{Arsenic pollution treatment technology}

\subsubsection{Precipitation method}

Sedimentation method mainly uses additional agents or energy to have chemical or physical effects with arsenic pollutants in the water to separate the precipitate or flocculate formed from the water so as to achieve the purpose of arsenic removal. Chemical precipitation method has the advantages of simple process, less investment and convenient operation, which is suitable for the wastewater with high arsenic content discharged from mines and enterprises. In the area with relatively poor economic conditions, it has high economic benefits and is the first choice for arsenic removal. However, this method requires a large amount of precipitants, which cannot be used to produce a large amount of arsenic-containing waste residue, and the long-term accumulation is easy to cause secondary pollution. Therefore, the application of this method is limited to some extent.

\subsubsection{Adsorption method}

Adsorption method is a simple and easy wastewater treatment technology, which is generally suitable for the water treatment system with large amount of treatment and low concentration. In this method, insoluble solid materials with high specific surface area are used as adsorbents to fix arsenic contaminants on the surface of water by physical adsorption, chemical adsorption or ion exchange, so as to achieve the purpose of arsenic removal.

\subsubsection{Oxidation method}

Trivalent arsenic is 60 times more toxic than pentavalent arsenic. And As(III) is much more difficult to remove than $\operatorname{As}(V)$. Many reagents have good removal effect on pentavalent arsenic, but poor removal effect on trivalent arsenic. Arsenic removal by oxidation is an effective method for arsenic trivalent, but the reaction kinetics is slow and the investment is high, so its application is limited to some extent.

\subsection{4 lon exchange method}

Ion exchange is also an effective method for arsenic removal. Suzuki et al. used monoclinic crystal hydrated zirconia to fill the porous resin, which could reduce the concentration of arsenic to $0.1 \mathrm{mg} / \mathrm{L}$, meeting the industrial emission standard ${ }^{[9]}$. However, because the ion exchange method can only treat the wastewater with low concentration, large amount of treatment, simple composition and high recovery value, its treatment process is more complex and the cost is high, so it is difficult to be commercialized.

\subsubsection{Biological arsenic removal technology}

Arsenic is not only enriched by organisms, but also oxidized and methylated by those organisms. Since the toxicity of methylated arsenic is much lower than that of inorganic arsenic, the process of arsenic enrichment by microorganisms in water is also a process of arsenic degradation and detoxification. Using this characteristic, the wastewater containing high concentration arsenic can be treated by biochemical method.

In addition to the main arsenic removal methods introduced above, according to the nature of wastewater and the development of new environmental protection technology, people have also tried some other arsenic removal technologies, such as electrolysis, solvent extraction, membrane separation, etc. The advantages and disadvantages of common processing techniques are shown in Table 1.

Table 1. Processing technology advantages and disadvantages

\begin{tabular}{|l|l|l|}
\hline \multicolumn{1}{|c|}{ technology } & \multicolumn{1}{|c|}{ advantages } & \multicolumn{1}{c|}{ disadvantages } \\
\hline Ion exchange method & $\begin{array}{l}\text { Arsenic removal efficiency is } \\
\text { high, can recover adsorbed } \\
\text { arsenic. }\end{array}$ & $\begin{array}{l}\text { High investment, complex } \\
\text { process, high operating cost, } \\
\text { the need for ion exchange resin } \\
\text { regeneration or backwashing. }\end{array}$ \\
\hline Membrane separation & $\begin{array}{l}\text { No secondary pollution, } \\
\text { arsenic can be recycled, energy } \\
\text { saving, normal temperature can } \\
\text { be operated. }\end{array}$ & $\begin{array}{l}\text { The production operation has } \\
\text { high investment, complex } \\
\text { management and needs a large } \\
\text { amount of backflow water. }\end{array}$ \\
\hline Biological methods & $\begin{array}{l}\text { No secondary pollution, low } \\
\text { cost. }\end{array}$ & $\begin{array}{l}\text { The technology is not yet } \\
\text { mature and the capital } \\
\text { construction cost is high. }\end{array}$ \\
\hline simple process. & $\begin{array}{l}\text { Simple process, low cost, } \\
\text { simple operation. }\end{array}$ & $\begin{array}{l}\text { High cost, difficult to collect } \\
\text { and treat leachate, easy to } \\
\text { cause secondary pollution. }\end{array}$ \\
\hline Precipitation method & $\begin{array}{l}\text { not complex environment is } \\
\text { arsenic and produces a large } \\
\text { number of other compounds. }\end{array}$ \\
\hline
\end{tabular}




\section{Application of manganese oxides in arsenic pollution treatment}

Manganese oxide is a strong abiotic oxidant, which has been proved to oxidize $\mathrm{As}(\mathrm{III}), \mathrm{Fe}(\mathrm{II}), \mathrm{Co}(\mathrm{II}), \mathrm{U}(\mathrm{IV})$, $\mathrm{Cr}$ (III) and organic matter ${ }^{[10]}$. Manganese rich formations are usually formed in areas with frequent fluctuations of groundwater level, such As shallow sea areas and shallow aquifers ${ }^{[11]}$. The deposition process of manganese rich materials in alluvial and flood plains also produces manganese rich environments ${ }^{[12]}$. The important natural manganese oxides include sodium water manganese minerals $\left([\mathrm{Na}, \mathrm{Ca}, \mathrm{Mn}(\mathrm{II})] \mathrm{Mn}_{7} \mathrm{O}_{14} \cdot 2.8 \mathrm{H}_{2} \mathrm{O}\right)$, spodumene $\left(\mathrm{LiAl}_{2}\left[\mathrm{Mn}(\mathrm{IV})_{2} \mathrm{Mn}(\mathrm{III})\right] \mathrm{O}_{6}(\mathrm{OH})_{6}\right)$ (double-layer structure), barium magnesium manganese ore $((\mathrm{Ca}, \mathrm{Na}$, K) $0.3 \sim 0.5[\mathrm{Mn}(\mathrm{IV}), \mathrm{Mn}(\mathrm{III}) \text { ), } \mathrm{Mg}]_{6} \mathrm{O}_{12} \cdot 3 \sim 4.5 \mathrm{H}_{2} \mathrm{O}$ ) (tunnel structure), and its low zero charge (pH1.7 3.5) make it an effective adsorbent for various heavy metals ( $\mathrm{Zn}, \mathrm{Ni}, \mathrm{Co}$ and $\mathrm{Pb})^{[13]}$. The reduction of manganese oxide is thermodynamically more advantageous than Fe(III) and $\mathrm{As}(\mathrm{V})$ because of its relatively high REDOX potential (about $400 \mathrm{mV})^{[14]}$. Manganese oxides have REDOX chemical properties similar to iron, and can rapidly oxidize As(III) and Fe(II) under oxidizing conditions, and are strongly associated with the fixation/migration of As in the oxygen-containing/hypoxic cycle of soil and sediments ${ }^{[15]}$.

Manning B A et al. ${ }^{[16]}$ used both a conventional stirred reaction apparatus and extended X-ray absorption fine structure (EXAFS) spectroscopy to investigate the reactions of $\mathrm{As}(\mathrm{III})$ and $\mathrm{As}(\mathrm{V})$ with synthetic birnessite $\left(\mathrm{MnO}_{2}\right)$. Stirred reactor experiments indicate that As(III) is oxidized by $\mathrm{MnO}_{2}$ followed by the adsorption of the $\mathrm{As}(\mathrm{V})$ reaction product on the $\mathrm{MnO}_{2}$ solid phase. The As(V)-Mn interatomic distance determined by EXAFS analysis for both $\mathrm{As}(\mathrm{III})$ - and $\mathrm{As}(\mathrm{V})$-treated $\mathrm{MnO}_{2}$ was $3.22 \AA$, giving evidence for the formation of $\mathrm{As}(\mathrm{V})$ adsorption complexes on $\mathrm{MnO}_{2}$ crystallite surfaces.

Bai Dekui et al. [17] synthesized three minerals, manganese oxide, iron oxide and alumina, and used iron oxide and manganese oxide As adsorbents to study the influence of $\mathrm{pH}$ value, ionic strength and time on the adsorption of As(III), and discussed the saturated adsorption capacity and isothermal adsorption experiments of As(III) by manganese oxide, iron oxide and alumina. The conclusions are As follows: 1) Under the optimized conditions, the order of saturated adsorption capacity of manganese oxide, iron oxide and alumina for As(III) is: manganese oxide $>$ iron oxide $>$ alumina. 2) $\mathrm{pH}$ had little effect on the adsorption of As(III) by manganese oxide, and the effect of $\mathrm{pH} 3.5 \sim 8.5$ on the adsorption of As(III) by iron oxide fluctuated little in a wide range. When $\mathrm{pH}<3.5$ or $\mathrm{pH}>8.5$, the adsorption rate of $\mathrm{As}$ (III) by iron oxide decreased. The ionic strength has little effect on the adsorption of $\mathrm{As}$ (III) by the oxide. The adsorption reaction between the two is a rapid reaction, and the adsorption equilibrium is reached about $30 \mathrm{~min}$.

Tournassat, $\mathrm{C}$ et al. ${ }^{[18]}$ studied the oxidation products of $\mathrm{As}(\mathrm{III})$ into $\mathrm{As}(\mathrm{V})$ in $0.011 \mathrm{M}$ arsenite suspension of a well-crystallized hexagonal sodium hydro-manganese ore (H-hydro-sodium hydro-manganese ore, $2.7 \mathrm{~g} \cdot 1^{-1}$ ) with $\mathrm{pH}$
5 by solution chemistry technique. The reactions were investigated by scanning electron microscopy, energy dispersion spectroscopy (SEM-EDS), atomic force microscopy (AFM) and X-ray absorption near edge structure spectroscopy (XANES). The conclusions are as follows: 1) manganese arsenate precipitates and forms long fibers, which gather on the surface of $\mathrm{H}$ - water sodium manganese ore. 2) Oxidation reaction transforms toxic substance As(III) into less toxic water-based substance. 3) The high crystallinity of sodium hydrochloride samples results in a lower depletion rate of As(III) than that measured in previous studies. 4) The surface reaction site may be located at the edge of the water-sodium-manganese ore layer, rather than at the base surface.

Liu Xiuying et al. ${ }^{[19]}$ modified natural manganese ore with TiCl4 and optimized the modification conditions. The experimental results show that the best modification conditions are as follows: TiCl4 concentration is $10 \mathrm{mg} / \mathrm{L}$, soaking time is $18 \mathrm{~h}, \mathrm{pH}=3.05$, and oscillating adsorption time is $1 \mathrm{~h}$ Compared with the removal efficiency of natural manganese ore (82. $95 \%$ and $77.93 \%$ ), the removal rates of As ( iii ) and As ( $v$ ) by modified manganese ore can reach $94.87 \%$ and $99.31 \%$ respectively, and the corresponding saturated adsorption amounts are $3.48 \mathrm{mg} / \mathrm{g}$ and $31.25 \mathrm{mg} / \mathrm{g}$ respectively, which are higher than those of natural manganese ore. The adsorption of modified manganese ore for As ( iii ) accords with Freundlich isothermal adsorption model, and the adsorption of As ( $v$ ) accords with Langmuir isothermal adsorption model.

Zhang Fan et al. ${ }^{[20]}$ studied the surface characteristics and arsenic removal performance of active iron and manganese oxide filter membrane prepared by chemical membrane hanging method. The results show that the pseudo-second-order reaction kinetic equation $\left(\mathrm{R}_{2}=0.922\right)$ can be used to characterize the adsorption process of As $(\mathrm{V})$ by the active Fe-Mn composite oxide. The adsorption isotherm conforms to Langmuir equation $\left(\mathrm{R}_{2}=0.971\right)$, and the saturated adsorption capacity is $11.94 \mathrm{mg} / \mathrm{g}$. The PHZPC of active iron and manganese oxide filter membrane is about 2.5. Carbonate in natural underground water has a strong inhibition effect on the adsorption and removal of arsenic, while other co-existing anions and cations have little effect on the removal of arsenic in neutral water environment. In the process of column test, the concentration of arsenic in the final effluent is reduced to zero after the groundwater with $\mathrm{As}(\mathrm{V})$ concentration of 200 and $280 \mu \mathrm{g} / \mathrm{L}$ is treated by the filter column, and the arsenic removal effect is good.

\section{Conclusions and perspectives}

(1) Different areas have different levels of pollution, sources of pollution and pollution objects. When using manganese oxides to treat pollution, a treatment plan suitable for different objects should be developed according to the local actual situation.

(2) The treatment of arsenic pollution by manganese oxide alone is not complete. When using manganese oxide to treat arsenic pollution, it should be combined with other 
treatment methods, such as Fe-Mn oxide activated carbon, which combines physical method and chemical method.

(3) The oxidation method has slow reaction kinetics and high investment, so the process of treating arsenic pollution by manganese oxide should be optimized to reduce the cost.

\section{Acknowledgments}

The authors thank the financial supports from the Guilin Science and Technology Project (20190219-3).

\section{References}

1. T. Agusa, T. Kunito, J. Fujihara, et al. Contamination by arsenic and other trace elements in tube-well water and its risk assessment to humans in Hanoi, Vietnam. Environmental Pollution. J. 139, 95-106(2006)

2. J. Bundschuh, B. Farias, R. Martin, et al. Groundwater arsenic in the Chaco-Pampean Plain, Argentina, case study from Robles county, Santiago del Estero Province. Applied Geochemistry. J. 19, 231-243 (2004)

3. M. M. Rahman, M. K. Sengupta, S. Ahamed, et al. The magnitude of arsenic contamination in groundwater and its health effects to the inhabitants of the Jalangi - one of the 85 arsenic affected blocks in West Bengal, India. Science of the Total Environment. J. 338, 189-200 (2005)

4. M. M. Karim. Arsenic in groundwater and health problems in Bangladesh. Water Research. J. 34, 304310 (2000)

5. K. Z. Benis, A. M. Damuchali, J. Soltan, et al. Treatment of aqueous arsenic - A review of biochar modification methods. Science of The Total Environment. J. 739, 139750 (2020)

6. F. J. Zhao, Y. Ma, Y. G. Zhu, et al. Soil Contamination in China, Current Status and Mitigation Strategies. Environmental Science \& Technology. J. 49, 750-759 (2015)

7. G. Li, G. X. Sun, P. N. Williams, et al. Inorganic arsenic in Chinese food and its cancer risk. Environment International. J. 37, 1219-1225 (2011)

8. P. L. Smedley, D. G. Kinniburgh. Arsenic in Groundwater and the Environment. essentials of medical geology. J. 296, 279-310 (2013)

9. T. M. Suzuki, J. O. Bomani, H. Matsunaga, et al. Removal of As(III) and As(V) by a Porous Spherical Resin Loaded with Monoclinic Hydrous Zirconium Oxide. Chemistry Letters. J, , 1997, 1119-1120 (2005)

10. Z. Wang, S. W. Lee, P. Kapoor, et al. Uraninite oxidation and dissolution induced by manganese oxide, A redox reaction between two insoluble minerals. Geochimica Et Cosmochimica Acta. J. 100, 24-40 (2013)

11. F. Schäffner, D. Merten , K. Pollok, et al. Fast formation of supergene Mn oxides/hydroxides under acidic conditions in the oxic/anoxic transition zone of a shallow aquifer. Environmental Science and Pollution Research. J. 22, 19362-19375 (2015)

12. Mandaliev, N. Petar, Mikutta, et al. Arsenic Species Formed from Arsenopyrite Weathering along a Contamination Gradient in Circumneutral River Floodplain Soils. Environmental Science \& Technology. J. 48, 208-217 (2014)

13. M. Zhu, M. Ginder-vogel, D. L. Sparks. Ni(II) sorption on biogenic Mn-oxides with varying $\mathrm{Mn}$ octahedral layer structure. Environmental Science \& Technology. J. 44, 4472-4478 (2010)

14. T. Borch, R. Kretzschmar, A. Kappler, et al. Biogeochemical redox processes and their impact on contaminant dynamics. Environmental Science \& Technology. J. 44, 15-23 (2010)

15. Makino, Tomoyuki, Suda, et al. Functional effects of manganese and iron oxides on the dynamics of trace elements in soils with a special focus on arsenic and cadmium, A review. Geoderma, An International Journal of Soil Science. J. 270, 68-75 (2016)

16. B. A. Manning, S. E. Fendorf, B. Bostick, et al. Arsenic(III) Oxidation and Arsenic(V) Adsorption Reactions on Synthetic Birnessite. Environmental Science and Technology. J. 36, 976-981 (2002)

17. B. Dekui, X. P. Zhu, Y. Y. Wang, et al. Study on the adsorption behavior of manganese oxide, iron oxide and alumina to arsenic ( III ). Rock and mineral analysis. J. 29, 55-60 (2010)

18. C. Tournassat, L. Charlet, D. B. Osbach, et al. Arsenic(III) oxidation by birnessite and precipitation of manganese(II) arsenate. Environmental Science \& Technology. J. 36, 493-500 (2002)

19. X. Y. Liu, Y. B. Huang, L. L. WANG, et al. Study on arsenic removal effect and mechanism of titanium modified manganese ore. Environmental engineering. J. 29, 46-49 (2011)

20. F. Zhang, Y. T. Huang, Y. Chen, et al. Study on the adsorption and removal of arsenic by activated Fe-Mn composite oxide filter membrane. China water \& wastewater. J. 33, 66-70 (2017) 